\title{
PERAN DAN TANGGUNG JAWAB DEWAN PENGAWAS SYARIAH (DPS) TERHADAP BANK PEMBIAYAAN RAKYAT SYARIAH (BPRS) DANA SEJAHTRA YOGYAKARTA
}

\author{
Agus Salihin \\ UIN Sunan Kalijaga Yogyakarta \\ Email: agussalihin03@gmail.com
}

\begin{abstract}
The purpose of this study is to discuss how the Role and Responsibilities of the Sharia Supervisory Board (DPS) Against the Syariah Prosperous Bank (SRB) of the Yogyakarta Prosperous Fund. This type of research is field research with a descriptive qualitative approach. The object of research is on the SRB in Yogyakarta. The data collection techniques include observation, interview and documentation. While the data analysis technique, researchers conducted a qualitative analysis by describing the results of field observations, observations and documentation. From the results of the study obtained the answer that the supervision carried out by the Sharia Supervisory Board (DPS) of the Syariah Prosperous Credit Bank (SRB) Yogyakarta Prosperous Fund is not yet fully maximized. In fact, only a small proportion of them have really conducted good supervision. The DPS's awareness of their responsibilities is still not fully realized, which in the end the DPS's participation in the Bank's daily activities cannot be done, even the DPS's arrival to the BPRS to conduct supervision is also very rarely done.
\end{abstract}

Keywords:Role, Responsibilities, DPS, SRB Abstrak :Tujuan penelitian ini untuk membahas tentang bagaimana Peran Dan Tanggung Jawab Dewan
Pengawas Syariah (DPS) Terhadap Bank Pembiayaan Rakyat Syariah (BPRS) Dana Sejahtera
Yogyakarta. Jenis penelitian ini merupakan penelitian lapangan dengan pendekatan kualitatif
deskriptif. Objek penelitian terletak pada BPRS di Yogyakarta. Adapun teknik pengumpulan data
berupa, Observasi, Wawancara dan Dokumentasi. Sedangkan teknik analisis data, peneliti melakukan
analisis secara kualititaif dengan mendeskripsikan hasil pengamatan lapangan, observasi dan
dokumentasi. Dari hasil penelitian diperoleh jawaban bahwa pengawasan yang dilakukan oleh
Dewan Pengawas Syariah (DPS) terhadap Bank Perkreditan Rakyat Syariah (BPRS) Dana Sejahtera
Yogyakarta belum sepenuhnya maksimal. Bahkan hanya sebagian kecil yang sudah benar-benar
melakukan pengawasan dengan baik. Kesadaran DPS atas tanggung jwabnya masih belum
sepenuhnya disadari, yang pada akhirnya keikutsertaan DPS dalam kegiatan sehari-hari Bank tidak
bisa dilakukan, bahkan kedatangan DPS terhadap BPRS untuk melakukan pengawasan juga sangat
jarang dilakukan.

\section{A. PENDAHULUAN}

Pertumbuhan perbankan syariah di Indonesia kini sudah terbukti secara nyata melalui banyaknya bermunculan institusi keuangan syariah di Indonesia. Hal ini akan berdampak pada persaingan antar pelaku bisnis perbankan, baik bank konvensional maupun bank syariah. $^{1}$

Bank syariah menawarkan alternatif jasa perbankan dengan sistem imbalan berupa

${ }^{1}$ Amimah Oktarina, "Program Corporate Sosial Responsibility Perbankan Syariah di Bidang Pengolahan Ikan Sebagai Alternatif Pemberdayaan UMKM Jangka Panjang”, Jurnal Al-Intaj, Vol.II No.2, 2016, hlm. 121-132 
bagi hasil. System ini menerapkan prinsip keadilan antara pihak bank dan nasabah. Bermula dari jasa penghimpunan dana masyarakat dalam bentuk tabungan dengan prinsip syariah, kini bank syariah mulai merambah bisnis pembiayaan untuk modal usaha maupun pembiayaan yang bersifat konsumtif seperti pembiayaan pemilikan rumah dan pemilikan kendaraan.

Aspek kesesuaian dengan syariah merupakan aspek utama dan mendasar yang membedakan antara bank syariah dengan bank konvensional. ${ }^{2}$ Hasil penelitian bank Indonesia bersama beberapa lembaga penelitian perguruan tinggi negeri di pulau jawa tentang potensi, prefrensi, dan prilaku masyarakat terhadap bank syariah di pulau jawa pada tahun 2000, menunjukkan bahwa salah satu alasan utama masyarakat memilih bank syariah adalah kehalalan produk dan jasa serta sistem bank syariah yang sesuai dengan prinsip-prinsip syariah. $^{3}$ Selain itu akad-akad yang digunakan berdasarkan prinsip syariah yang telah ditapkan oleh Dewan Pengawas Syariah (DPS). ${ }^{4}$ Untuk memastikan bahwa oprasional bank syariah telah memenuhi prinsip-prinsip syariah, maka bank syariah harus memiliki institusi internal independen yang khusus dalam pengawasan kepatuhan syariah yaitu Dewan Pengawas Syariah (DPS). Ada tiga alasan mengapa Dewan Pengawas Syariah mempunyai peran penting dalam bank syariah yaitu; Pertama, menentukan tingkat kredibilitas bank syariah. Kedua, menjadi unsur utama dalam menciptakan jaminan kepatuhan syariah. Ketiga, menjadi salah satu pilar utama dalam pelaksanaan Good Corporate Govermance (GCG) bank syariah. $^{5}$

Bank Pembiayaan Rakyat Syariah (BPRS) adalah salah satu bagian dari perbankan syariah yang ada di seluruh nusantara indonesia. Untuk meningkatkan kualitas kerja bank syariah di indonesia maka perlu adanya Dewan Pengawas Syariah (DPS) dengan tujuan untuk mengetahui sejauhmana perbankan syariah di indonesia dalam menjalankan kegiatan perbankannya telah sesuai dengan prinsip-prinsip syariah. Selain itu keberadaan Dewan Pengawas Syariah (DPS) dapat mampu memastikan kepatuhan terhadap prinsip syariah pada setiap aktivitas bank. ${ }^{6}$

Peran utama DPS menurut Syafi'i adalah mengawasi jalannya oprasionalnya bank sehari-hari agar selalu sesuai dengan ketentuan-ketentuan syariah. ${ }^{7}$ Dengan kata lain DPS berperan penuh terhadap kinerja bank syariah. Peran dan fungsi DPS harus betul-betul dioptimalkan, karena akan sangat mengkhawatirkan jika masih banyak praktik perbankan syariah yang menyimpang dari ketentuan syariah Islam. ${ }^{8}$

Perbaikan lingkungan eksternal Dewan Pengawas Syariah menjadi tanggung jawab

\footnotetext{
${ }^{2}$ Muhammad, Manajemen Keuangan Syariah Analisis Fiqih \& Keuangan, (Yogyakarta: UPP STIM YKPN, 2016), hlm. 14 2007), hlm. 90

${ }^{3}$ Heri Sudarsono, Bank dan Lembaga Keuangan Syariah Deskripsi dan Ilustrasi, (Yogyakarta: Ekonisia,

${ }^{4}$ Nonie Afrianty, "Kedudukan Jaminan dan Denda Pada Pembiayaan Bank Syariah", Jurnal Al-Intaj, Vol.IV No.2, 2018, hlm. 224-244

${ }^{5}$ Andi Prabowo, “Analisis Yiridis Peran dan Tanggung Jawab Dewan Pengawas Syariah Sebelum dan Sesudah diberlakukannnya UU 21 Tahun 2008 Tentang Perbankan Syariah”, Makalah UGM Yogyakarta, 2009, hlm.9

${ }^{6}$ Eeng Julio Efrianto, "Prosedur dan Biaya Audit: Studi Komparatif Konvensional dan Syariah", Jurnal Al-Intaj, Vol.V No.I, 2019, hlm.152-165

${ }^{7}$ M. Syafi' I Antonio, Bank Syariah dari Teori ke Praktik, (Jakarta: Gema Insani, 2001), Cet.1, hlm. 234

${ }^{8}$ Neneng Nurhasanah, “Optimalisasi Peran Dewan Pengawas Syariah (DPS) di Lembaga Keuangan Syariah”, Journal Syariah Hukum UNISBA, Vol.XIII No.3, 2011, hlm. 218-231
} 
utama bank Indonesia sebagai regulator untuk menciptakan mekanisme pengawasan syariah yang efektif dan efisien sehingga terbentuk perbankan syariah Indonesia yang sehat, efisien dan sesuai syariah. Sedangkan tanggung jawab perbaikan lingkungan internal Dewan Pengawas Syariah menjadi tanggung jawab Dewan Pengawas Syariah sendiri dan manajmen bank syariah untuk menciptakan system jaminan kepatuhan syariah yang efisien dan efektif untuk membangun kepercayaan masyarakat terhadap bank syariah.

Berdasarkan uraian diatas maka tujuan penelitian ini untuk membahas tentang bagaimana "Peran Dan Tanggung Jawab Dewan Pengawas Syariah (DPS) Terhadap Bank Pembiayaan Rakyat Syariah (BPRS) Dana Sejahtera Yogyakarta“.

\section{B. METODE PENELITIAN}

Penelitian ini merupakan penelitian lapangan (Field Research) dengan pendekatan kualitatif. Adapun Objek penelitian terletak pada BPRS Dana Sejahtera Yogyakarta. Teknik pengumpulan data dalam penelitian ini menggunakan teknik Observasi, Wawancara, dan Dokumentasi.

Teknik analisis data dalam penelitian ini menggunakan tiga teknik yaitu; Pertama, teknik Data Reduction (Reduksi data) yang berisikan tentang rangkuman isi, atau topik permasalahan yang sedang diteliti. Kedua, Data Display (Penyajian Data) yang berisikan tentang penyajian data dari hasil penelitian. Ketiga, Conclusion Drawing,yang bertujuan untuk menyimpulkan hasil penelitian yang telah di analisis

\section{HASIL DAN PEMBAHASAN}

\section{Peran dan Tanggungjawab DPS}

\section{a. Peran DPS}

Dalam melaksanakan tugas dan fungsinya DPS akan dibantu oleh internal syari'a review yang dilakukan oleh internal auditor untuk menilai kepatuhan bank syariah atas prinsip-prinsip dan aturan syariah. Dewan pengawas syariah akan memberikan arahan dan perintah-perintah kepada internal auditor untuk melaksanankan internal syariah review, dan melaporkan hasil penilaian dan pengujiannya kepada dewan pengawas syariah. Dalam hal ini internal auditor berfungsi untuk menjambatani komunikasi antara DPS dan manajmen dalam melakukan control atas seluruh aktifitas bank agar sesuai dengan prinsip-prinsip dan aturan syariah. ${ }^{9}$ Adapun Tugas dan wewenang tersebut secara lebih terperinci dapat dijabarkan sebagai berikut:

1) Memberikan pedoman dan garis besar syariah baik untuk menerapkan maupun menyalurkan dana serta kegiatan bank lainnya

2) Mengadakan perbaikan seandainya suatu produk yang sedang dijalankan dinilai bertantangan dengan syariah

3) Memberikan jawaban dalam bentuk fatwa terhadap permasalahan yang diajukan atau dihadapi oleh pihak eksekutif dan operasi.

4) Memeriksa buku laporan tahunan dan memberikan pernyataan tentang kesesuaian syariah

${ }^{9}$ Wawasan Summitro, Assas-Assas Perbankan Islam \& Lembaga-Lembaga Terkait: BAMUI, Takaful, dan Pasar Modal Syariah di Indonesia, (Jakarta, PT Raja Grafindo Persada, 2004), hlm. 157-159 
dari semua produk dan operasi selama tahun berjalan.

Dalam rangka menjalankan tugas-tugas tersebut DPS berhak dan mempunyai wewenang untuk:

1) Bersama-sama maupun sendiri-sendiri dalam jam kantor perusahaan untuk menanyakan atau memeriksa segala prodek dan aktifitas perusahaan ditinjau dari sudut pandang islam.

2) Untuk hal tersebut direksi dan apparat bank dan lainnya wajib untuk memberikan penjelasan tentang segala hal yang ditanyakan oleh DPS.

Dalam keputusan DSN mengatur mengenai tugas dan fungsi DPS yaitu mengawasi kegiatan usaha lembaga keuangan syariah agar sesuai dengan ketentuan dan prinsip syariah yang telah di fatwakan oleh DSN. Dan fungsi utama DPS adalah sebagai penasehat dan pemberi saran kepada direksi, pimpinan unit usaha syariah dan pimpinan kantor cabang syariah mengenai hala-hal yang terkait dengan aspek syariah serta sebagai mediator antara lembaga keuangan syariah dengan DSN dalam mengkomunikasikan usul dan saran pengembangan produk dan jasa dari lembaga keuangan syariah yang memerlukan kajian dan fatwa dari DSN. Selain itu fungsi DPS adalah sebagai berikut:

1) Sebagai penasehat dan pemberi saran sebagai dewan direksi, pimpinan unit usaha syariah dan pimpinan kantor cabang syariah mengenai hal-hal yang terkait dengan aspek syariah

2) Sebagai mediator antara lembaga keuangan syariah dengan DSN dalam mengkomunikasikan usul dan saran pengembangan produk dan jasa dari lembaga keuangan syariah yang memerlukan kajian dan fatwa dari DSN. ${ }^{10}$

\section{b. Tanggung Jawab DPS}

Selanjutnya berdasarkan peraturan bank Indonesia (PBI) No.6/17/PBI/2004, PBI No.6/24/PBI/2004 dan PBI No.8/3/PBI/2006 DPS bertanggung jawab menyampaikan laporan pengawasan syariah secara periodic terkait dengan tugas DPS, dan sebagai tindak lanjut amanat dari Ijtima'Sanawi (Annual Meeting) DPS Pertama di Jakarta tanggal 8-11 september 2004, mengenai pedoman pengawasan syariah dan tatacara pelaporan hasil pengawasan bagi dewan pengawas syariah sebagai petunjuk pelaksanaan tugas, wewenang, dan tanggung jawab DPS bagi perbankan syariah merupakan perangkat kerja yang mendesak untuk diwujudkan. Pedoman pengawasan syariah dan tata cara pelaporan hasil pengawasan bagi dewan pengawas syariah ini disusun dengan tujuan untuk menjadi acuan minimal bagi anggota DPS dalam menjalankan fungsi pengawasan syariah terhadap kegiatan operasional bank syariah. Dalam melaksanakan tugas, wewenang dan tanggung jawab pengawasan tersebut DPS mengacu kepada fatwa DSN-MUI dan ketentuan bank Indonesia sehingga anggota DPS mempunyai kesamaan pandang dan sikap dalam menanggapi dan menangani setiap permasalahan syariah yang dihadapi oleh bank syariah.

Dalam rangka memenuhi standar good corporate govermance perbankan syariah dalam aspek akuntabilitas dan transparansi, diperlukan adanya pedoman kerja dan mekanisme pengawasan aspek syariah bagi DPS sebagai pihak terafiliasi sebagaimana dimaksud dalam undang-undang perbankan. Sama halnya dengan PBI No.6/17/PBI/2004 tanggal 1 juli 2004 tentang bank perkreditan bank rakyat berdasarkan prinsip syariah, PBI No.6/24/PBI/2004 tanggal 14 oktober 2004 tentang bang umum yang melaksanakan kegiatan usaha berdasarkan

\footnotetext{
${ }^{10}$ Desi Isnaini, “Studi Kedudukan dan Peran Dewan Pengawas Syariah di Koperasi Syariah”, Jurnal AlIntaj, Vol.IV No.1, 2018, hlm. 155-175
} 
perinsip syariah sebagaimana telah diubah dengan PBI No.7/35/PBI/2005 tanggal 29 september 2005 tentang bank umum yang melaksanakan kegiatan usaha berdasrkan prinsip syariah dan PBI No.8/3/PBI/2006 tanggal 30 januari 2006 tentang perubahan kegiatan usaha bank umum konvensional menjadi bank umum yang melaksanakan kegiatan usaha berdasarkan perinsip syariah dan pembukaan kantor bank yang melaksanakan kegiatan usaha berdasarkan prinsip syariah oleh bank umum konvensional. ${ }^{11}$ Mengenai pengertian dalam lampiran pengaturan bank Indonesia DPS adalah dewan yang melakukan pengawasan terhadap perinsip syariah dalam kegiatan usaha bank syariah yang dalam menjalankan fungsinya bertindak secara independen. DPS merupakan pihak terapiliasi dan bagian dari bank. Mengenai tugas, wewenang dan tanggung jawab DPS meliputi: ${ }^{12}$

1) Memastikan dan mengawasi kesesuaian operasional bank terhadap fatwa yang dikeluarkan oleh DSN-MUI

2) Menilai aspek syariah terhadap pedoman oprasional, dan produk yang dikeluarkan bank

3) Memberikan opini dari aspek syariah terhadap pelaksanaan operasional bank secara keseluruhan dalam laporan publikasi bank

4) Mengkaji produk dan jasa baru yang belum ada fatwa untuk dimintakan fatwa kepada DSN-MUI

5) Menyampaikan hasil pengawasan syariah sekurangnya setiap enam bulan.

\section{Kewenangan DPS Terhadap BPRS Dana Sejahtera Yogyakarta}

Dewan Pengawas Syariah (DPS) berwewenang untuk melakukan pengontrolan dan berwewenang pula untuk memberikan status hokum suatu produk dari BPRS yang diawasinya, apakah produk itu boleh (halal) atau tidak boleh (haram) untuk dipasarkan kepada nasabah dan masyarakat. DPS dalam memberikan status hokum tersebut mengacu pada Fatwa DSN-MUI, kemudian seandainya ada produk baru yang belum ada fatwanya, maka akan meminta fatwa kepada DSN-MUI. Artinya DPS juga bisa berinovasi untuk membuat suatu produk baru yang belum ada namun tetap harus meminta fatwa dari DSNMUI.

Dengan melihat praturan Bank Indonesia Nomor 6/17/PBI/2004 tanggal 1 juli 2004 tentang Bank Perkreditan Rakyat berdasarkan prinsip Syariah dan Praturan Bank Indonesia Nomor 6/24/PBI/2004 tanggal 14 oktober 2004 tentang Bank Umum yang melaksanakan kgiatan usahanya berdasarkan prinsip syariah. Praturan tersebut menjelaskan bawa Dewan Pengawas Syariah (DPS) memiliki tugas, wewnang dan tanggung jawab antara lain memastikan dan mengawasi kesesuaian kegiatan operasional bank terhadap fatwa yang dikeluarkan oleh Dewan Syariah Nasional (DSN), menilai aspek syariah terhadap pedoman oprasional dan produk yang dikeluarkan bank, memberikan opini dari aspek syariah terhadap pelaksanaan operasional bank secara keseluruhan dalam laporan publikasi bank, mengkaji produk dan jasa baru yang belum ada fatwa untuk dimintakan fatwa kepada DSN, dan menyampaikan laporan hasil pengawasan syariah.

Dewan pengawas syariah akan memberikan arahan dan printah-perintah kepada 2019, jam: 10:00

${ }^{11}$ PBI ini diambil dari Web Bank Indonesia, http://www.bi.go.id, diakses pada tanggal 19, Desember

${ }^{12}$ Dewi Anggadini, ”Mekanisme Pengawasan Dewan Pengawas Syariah dan Bank Indonesia Terhadap Bank Syariah", Majalah UNIKOM, Vol. XII, No. 1, 2012, hlm. 81 
internal auditor untuk melaksanankan internal syariah review, dan melaporkan hasil penilaian dan pengujiannya kepada Dewan Pengawas Syariah (DPS). Dalam hal ini internal auditor berfungsi untuk menjembatani komunikasi antara DPS dan manajmen dalam melakukan control atas seluruh aktivitas bank agar sesuai dengan prinsip-prinsip dan turan syariah.

Kewenangan DPS bagi BPRS Dana Sejahtera Yogyakarta adalah pada bagaimana DPS tersebut mengawasi BPRS-nya. Pada aplikasinya di lapongan pengawasan yang dilakukan oleh DPS masih belum sepenuhnya sempurna dilakukan, dengan kata lain belum maksimal. Penyebabnya ialah karena komunikasi antara DPS dengan BPRS masih belum berjalan dengan baik. Hal ini menyebabkan kedatangan DPS ke-BPRS untuk melakukan pengawasan menjadi optimal.

\section{Mekanisme Pengawasan DPS Terhadap BPRS Dana Sejahtera Yogyakarta}

DPS pada Perbankan Syariah memiliki peran penting dan strategis dalam penetapan prinsip syariah di perbankan syariah. DPS bertanggung jawab untuk memastikan semua produk dan prosedur bank syariah sesuai dengan prinsip syariah. Karena pentingnya peran DPS tersebut di perusahaan syariah dan lembaga perbankan syariah, yaitu UU No.21 tahun 2008 tentang Perbankan Syariah. Dengan demikian secara yuridis DPS di perusahaan perbankan menduduki posisi yang kuat, karena keberadaannya sangat penting dan strategis.

Dengan melihat kembali keterangan yang sudah dikemukakan di atas, tugas dan tanggung jawab DPS ialah:

a. Memberikan nasehat dan saran kepada direksi serta mengawasi kegiatan bank agar sesuai dengan prinsip syariah.

b. Menilai dan memastikan pemenuhan prinsip syariah atas pedoman dan oprasional dan produk yang dikeluarkan bank.

c. Mengawasi proses pengembangan produk baru bank

d. Meminta fatwa kepada DSN terkait adanya produk baru bank yang belum ada fatwanya.

e. Melakukan review secara berkala atas pemenuhan prinsip syariah terhadap mekanisme penghimpunan dana dan penyaluran dana serta penyaluran jasa bank

f. Meminta data dan informasi terkait dengan aspek syariah dengan satuan kerja bank dalam rangka pelaksanaan tugasnya.

Aktivitas Dewan Pengawas Syariah dalam melaksanakan pengawasan yang dilakukan diberbagai BPRS Dana Sejahtera Yogyakarta tentu mengacu pada Peraturan Bank Indonesia (PBI) yang berlaku dan khusus untuk melakukan pengawasan terhadap kesyariahan BPRS, baik dari segi akad, transaksi, produk dan sebagainya dan mengacu pada Fatwa Dewan Syariah Nasional Majlis Ulama Indonesia (DSN-MUI). Pada umumnya pengawasan DPS dibagi menjadi dua yaitu; Pengawasan Internal dan Pengawasan Eksternal. Pengawasan yang terpenting yang dilakukan oleh DPS adalah pengawasan Internal. Hal ini dikarenakan menyangkut kredibilitas BPRS yang diawasinya.

Dewan Pengawas Syariah merupakan satu dewan pakar ekonomi dan ulama yang menguasai bidang fiqih mu'ammalah (Islamic Commercial Jurisprudence) yang berdiri sendiri dan bertugas mengamati dan mengawasi operasional bank dan semua produkproduknya agar sesuai dengan ketentuan-ketentuan syariah islam. ${ }^{13}$ Dewan pengawas syariah

${ }^{13}$ Arofah Anik, "Peran dewan pengawas syariah terhadap pengawasan aspek syariah di baitul maal wa tamwil (bmt) Safinah Klaten”, Skripsi, Fakultas Syariah, Universitas Sebelas Maret, 2008 
(The Shari'a Supervisor Board) mesti melihat secara teliti bagaimana bentuk-bentuk akad yang dilaksanakan oleh institusi keuangan syariah. DPS melakukan pengawasan terhadap akad-akadnya, melakukan pengawasan terhadap transaksinya, terhadap oprasionalnya baik dengan nasabah maupun dengan pihak ketiga dan lain sebagainya yang menyangkut dengan BPRS tersebut. Artinya DPS itu harus mengawasi secara kaffah atau menyeluruh tentang semua yang diakukan oleh BPRS yang dinaunginya.

Menurut Briston, ada tiga cara Dewan Pengawas Syariah yaitu; ex ante auditing, ex post auditing dan perhitungan dan pembayaran zakat. Pertama, Ex ante auditing merupakan aktivitas pengawasan syariah dengan melakukan pemeriksaan terhadap berbagai kebijakan yang diambil dengan cara melakukan review terhadap keputusan-keputusan manajmen, dan melakukan review terhadap seluruh jenis kontrak yang dibuat oleh manajmen bank syariah dengan semua pihak. Tujuan pemeriksaan tersebut untuk mencegah bank syariah melakukan kontrak yang melanggar prinsip-prinsip syariah. Kedua, ex post auditing merupakan aktivitas pengawasan syariah dengan melakukan pemeriksaan terhadap laporan kegiatan dan laporan keuangan bank syariah. Tujuan pemeriksaan ini adalah untuk menelusuri kegiatan dan sumber-sumber keuangan bank syariah yang tidak sesuai dengan prinsip-prinsip syariah. Ketiga, Perhitungan dan pembayaran zakat merupakan aktivitas pengawasan syariah dengan memeriksa kebenaran bank syariah dalam menghitung zakat yang harus dikeluarkan dan memeriksa kebenaran dalam pembayaran zakat dengan ketentuan syariah. Tujuan pemeriksaan tersebut adalah untuk memastikan agar zakat atas segala usaha yang berkaitan dengan hasil usaha bank syariah telah dihitung dan dibayar secara benar oleh manajmen bank syariah. ${ }^{14}$

Berdasarkan hasil wawancara dapat dijelaskan bahwa, untuk mekanisme pengawasan yang dilakukan oleh DPS belum sempurna seperti yang diatur oleh Bank Indonesia dalam PBI-nya dan seperti yang tergambar diatas. DPS dalam melakukan pengawasan tidak bisa sepenuhnya dilakukan, hal ini karena keterbatasan waktu dan kesibukan DPS itu sendiri. ${ }^{15}$ Pendapat ini sejalan dengan penjelasan yang diungkapkan oleh Prof. Dr. H. Amir Mu'alim, MA bahwa DPS dalam melakukan pengawasan terhadap BPRS pada praktiknya dilapangan belum bisa terjadwal dengan baik, dengan alasan karena kesibukan DPS yang mobile dan banyak kegiatan. ${ }^{16}$

Kehadiran DPS di BPRS tentu angat berpengaruh besar terhadap pengawasan yang dilakukan oleh DPS. Tingkat rutinitas kehadiran DPS di BPRS tentu sangat diharapkan maksimal agar pemantauan dan pengawasan kesyariahan BPRS bisa berjalan dengan baik sehingga BPRS tersebut benar-benar menjadi Lembaga Keuangan Syariah yang benar-benar "Syariah". Selain itu kehadiran DPS terhadap BPRS juga berdampak pada bagaimana keterlibatan DPS dengan BPRS. Keterlibatan DPS tersebut dirasa sangat kurang terutama dalam hal transaksi dan kegiatan BPRS secara umum. Hal ini sangat di khawatirkan akan

\footnotetext{
${ }^{14}$ Siti Asmaul Usnah dan Noven Suparyogi, "Pandangan Mahasiswa Fakultas Ekonomi dan Bisnis Universitas Airlangga Tentang Kepatuhan Syariah di Bank Syariah”, Journal JESTT, Vol.II No.2, 2015, hlm. 147161

${ }^{15}$ Disampaikan oleh M. Hajar Dewantoro, M.Ag, DPS dari BPRS Dana Sejahtera pada tanggal 18 Desember, 2019, jam: 13:00

${ }^{16}$ Wawancara Dengan Prof. Dr. H. Amir Mu'alim, DPS dari BPRS FORMES, pada tanggal 19 Desember, 2019, jam: 14:15
} 
adanya terjadi penyimpangan kesyariahan BPRS itu sendiri. ${ }^{17}$

\section{Analisa Mekanisme Pengawasan DPS}

Pengawasan yang dilakukan DPS terhadap BPRS Dana Sejahtera Yogyakarta yaitu dengan datangnya DPS ke-BPRS yang diawalinya untuk melihat bagaimana antara BPRS dengan nasabah atau dengan perusahaan. Transaksi yang dilakukan BPRS jelas harus berbeda dengan BPR atau lembaga-lembaga keuangan yang bersifat konvensional. BPRS dengan membawa misi syariahnya tentu harus mengacu pada ajaran islam yang dibenarkan. Nilai syariah yang dibawa oleh BPRS menjadikan lembaga tersebut harus benar-benar menjaga keaslian dan kemurnian syariahnya. Oleh karenanya DPS-lah yang memberikan lampu hijau atau lampu merah bahkan lampu kuning terhadap kesyariahan transaksi yang akan atau telah dilakukan oleh BPRS.

Berbicara mengenai tanggung jawab, sebenarnya DPS bertanggung jawab penuh terhadap semua kegiatan yang dilakukan oleh BPRS-nya. Tagung jawab yang dipikul DPS bukan hanya semata-mata kepada Bank Indonesia dengan persemester sekali memberikan laporan, namun lebih dari itu DPS bertanggung jawab terhadap sifat keukhrowian BPRS-nya. Sifat BPRS terhadap DPS-nya hanyalah mengikuti tahapan apa yang diputuskan ketika pada transaksi DPS mengatakan hal itu haram tidak sesuai dengan syariah, maka BPRS tidak boleh menjalankannya. Sebaliknya ketika DPS mengatakan transaksi itu telah memenuhi prinsip syariah, maka BPRS dapat menjalankannya dengan baik.

Dari keterangan-keterangan diatas termasuk pada bagian tanggung jawab DPS terhadap BPRS. DPS adalah pemimpin kesyariahan suatu lembaga keuangan syariah (BPRS), meskipun yang kita tahu bahwa pimpinan di BPRS adalah adanya Direksi dan Dewan Komisaris, pada intinya tanggung jawab Direksi maupun Komisaris adalah bagaimana memajukan perusahaan tersebut menjadi lebih berkembang dan lebih banyak lagi keuntungan yang dihasilkan. Namun dari semuanya itu DPS mempunyai tanggung jawab yang lebih besar. Tanggung jawab terhadap BI karena harus melaporkan dan tanggung jawab terhadap Akhirat (Allah SWT). ${ }^{18}$

DPS sebagai pengawas dalam masalah kesyariahan BPRS tentu segala hasil kerjanya harus dilaporkan dan dimintai pertanggung jawaban. Seandainya ada BPRS yang menurut BI melanggar dari norma-norma syariah maka yang pertama kali dimintai pertanggung jawaban adalah DPS-nya. Dan begitu juga seandainya pertanggung jawabannya akan diminta diakhirat.

\section{KESIMPULAN}

Kredibilitas suatu bank syariah sangat ditentukan oleh tingkat kredibilitas DPS dalam masalah kinerja, independensi, dan kompetensi. Sehingga peran dan fungsi DPS harus dioptimalkan dalam pengawasan internal syariah untuk membangun jaminan kepatuhan syariah bagi seluruh stakeholder bank syariah di Indonesia. Langkah optimalisasi peran dan fungsi DPS dalam pengawasan internal syariah adalah dengan memperbaiki lingkungan

${ }^{17}$ Disampaikan Oleh Drs. H. M. Sularno, MA, DPS dari FORMES saat diwawancara pada tanggal 23 Desember, 2019, jam: 16:13

${ }^{18}$ Muhlish Usman, Kaidah-Kaidah Ushuliyah dan Fiqhiyah, (Jakarta: PT Raja Grafindo Persada,2003), hlm. 148 
eksternal dan internal DPS. Perbaikan lingkungan eksternal DPS menjadi tanggung jawab utama BI sebagai regulator yaitu menciptakan mekanisme pengawasan syariah yang efektif dan efisien, dan sesuai syariah. Sedangkan tanggung jawab perbaikan lingkungan internal DPS menjadi tanggung jawab DPS dan manajmen bank syariah untuk menciptakan system jaminan kepatuhan syariah yang efisien dan efektif untuk membangun kepercayaan masyarakat terhadap bank syariah.

\section{E. DAFTAR PUSTAKA}

Afrianty, Nonie. 2018. "Kedudukan Jaminan dan Denda Pada Pembiayaan Bank Syariah", Jurnal Al-Intaj, Vol.IV, No.2

Anggadini, Dewi. 2012. "Mekanisme Pengawasan Dewan Pengawas Syariah dan Bank Indonesia Terhadap Bank Syariah", Majalah UNIKOM, Vol. XII, No. 1

Antonio, M. Syafi’'I. 2001. Bank Syariah dari Teori ke Praktik. Jakarta: Gema Insani

Arofah, Anik. 2008. "Peran Dewan Pengawas Syariah Terhadap Pengawasan Aspek Syariah Di Baitul Maal Wa Tamwil (BMT) Safinah Klaten”. Skripsi. Fakultas Syariah. Universitas Sebelas Maret

Efrianto, Eeng Julio. 2019. "Prosedur dan Biaya Audit: Studi Komparatif Konvensional dan Syariah, Jurnal Al-Intaj, Vol.V No.1

Isnaini,Desi. 2018. "Studi Kedudukan dan Peran Dewan Pengawas Syariah di Koperasi Syariah", Jurnal Al-Intaj, Vol.IV No.1

Muhammad. 2016. Manajmen Keuangan Syariah Analisis Fiqih \& Keuangan. Yogyakarta: UPP STIM YKPN

Nurhasanah, Neneng. 2011. "Optimalisasi Peran Dewan Pengawas Syariah (DPS) di Lembaga Keuangan Syariah", Journal Syariah Hukum UNISBA, Vol.XIII. No.3

Oktarina, Amimah. 2016. "Program Corporate Sosial Responsibility Perbankan Syariah di Bidang Pengolahan Ikan Sebagai Alternatif Pemberdayaan UMKM Jangka Panjang”, Jurnal Al-Intaj, Vol.II, No.2

Prabowo, Andi. 2009. "Analisis Yiridis Peran dan Tanggung Jawab Dewan Pengawas Syariah Sebelum dan Sesudah diberlakukannnya UU 21 Tahun 2008 Tentang Perbankan Syariah". Makalah UGM Yogyakarta

Sudarsono, Heri. 2007. Bank dan Lembaga Keuangan Syariah Deskripsi dan Ilustrasi. Yogyakarta: EKONISIA

Summitro, Wawasan. 2004. Assas-Assas Perbankan Islam \& Lembaga-Lembaga Terkait: BAMUI, Takaful, dan Pasar Modal Syariah di Indonesia. Jakarta: PT Raja Grafindo Persada

Usman, Muhlish. 2003. Kaidah-Kaidah Ushuliyah dan Fiqhiyah, Jakarta: PT Raja Grafindo Persada

Usnah, Siti Asmaul. Noven Suparyogi. 2015. "Pandangan Mahasiswa Fakultas Ekonomi dan Bisnis Universitas Airlangga Tentang Kepatuhan Syariah di Bank Syariah”. Journal JESTT, Vol.II, No.2 